\title{
INTENSIFICATION OF LIQUID STEEL ACTIVE FLOW VOLUME IN ONE-STRAND TUNDISH USING A MODIFIED LADLE SHOURD
}

\author{
Michat Bartosiewicz*, Adam Cwudziński \\ Czestochowa University of Technology, Faculty of Production Engineering and \\ Materials Technology, Department of Metallurgy and Metals Technology, Armii \\ Krajowej 19 ave, 42-200 Częstochowa, Poland
}

Received 11.12.2019

Accepted 27.02.2020

\begin{abstract}
This work presents the numerical and physical simulation results of the liquid steel flow in the one-strand tundish. The results obtained during the numerical simulations and the water modeling results were compared to each other. Six types of turbulence models were tested. Among tested turbulence models the BSL k- $\omega$ was turned out the best correlating with the results from the laboratory experiments. Besides, the ladle shroud modification was proposed by the authors and the influence of the modified ladle shroud immersion depth in the liquid steel on the hydrodynamic structure in the tundish was checked. The ladle shroud modification depended on the expansion, narrowing, and re-expansion of the liquid steel feed stream. The four tundish variants with the four different ladle shroud immersion depths (at 0.1, 0.2, 0.3, and $0.4 \mathrm{~m}$ ) in the liquid steel were tested. The liquid steel flow volumes were calculated and according to the generated active flow volume, the most beneficial research case was indicated. The tundish variant with the ladle shroud immersion depth of $0.3 \mathrm{~m}$ in the liquid steel was characterized by the lowest stagnant flow volume. The numerical simulations were performed by using the Ansys-Fluent computer program.
\end{abstract}

Keywords: continuous steel casting; tundish; ladle shroud; numerical simulations; physical simulations; turbulence models.

\section{Introduction}

A stand of continuous steel casting (CSC) consists of a steel ladle, tundish, mold and secondary cooling zone. A tundish provides permanent liquid steel flow from ladle to casting mold, where the solidification process is initiated. Therefore, a tundish is an indispensable device of a continuous steel casting line, and the improvement

*Corresponding author: Michał Bartosiewicz, bartosiewicz.michal@wip.pcz.pl 
of tundish working conditions can bring important benefits from the viewpoint of the semi-finished steel product quality, the efficiency of steel casting, and safety of a CSC staff. In the tundish, the liquid steel is protected from the oxygen adsorption and the excessive heat losses by the tundish powder in the considered object. Besides, the liquid steel stream between ladle and tundish is protected by a ladle shroud. Widely used a conventional ladle shroud is characterized by a simple construction and insignificant influence on the liquid steel flow hydrodynamic structure in the tundish. In last time, the ladle shroud was being considered as a flow control device (FCD) by the modification of its construction. The modified ladle shroud was consisted of expanding [1, 2], expanding-compressing $[3,4]$ and inhibiting [5] the liquid steel feeding stream. Also, the ladle shroud was equipped with the vacuum chamber $[6,7]$. In general, all of the cited ladle shroud propositions bring the lower liquid steel flow velocity inside the ladle shroud, which decreases the turbulence motion in the tundish working space. Therefore, phenomena such as slag entrapment into liquid steel may be reduced. Likewise, the widening of the ladle shroud space can provide the limitation of the destructive effect of the blowback phenomenon. Also, the installation of the vacuum chamber around the ladle shroud is a different interference in the considered object. This proposal is based on the directing of the liquid steel streams towards the vacuum chamber, which in effect, inhibits the flow of the liquid steel in the area of the ladle shroud. This solution reduces the slag eye phenomenon to practically zero.

The improvement of liquid steel flow hydrodynamic structure mainly bases on decreasing the stagnant flow volume in the tundish. The occurrence of this type the liquid steel flow volume is adversely due to the low efficiency of the removing process of the non-metallic inclusions or the heat and the chemical liquid steel homogenization in the tundish. Therefore, the liquid steel flow volume can be activated by a modifying tundish working space using FCD $[8,9]$.

Research tests in the industrial conditions are fraught with difficulties such as continuity of the casting process, high costs and opacity of the liquid steel. Consequently, on widely scale the method of computational fluid dynamics (CFD) to simulate the liquid steel flow through the tundish is adopted. The used mathematical model in the computer program such as Ansys-Fluent, can simulate the liquid steel flow hydrodynamic structure with more and more accuracy. Furthermore, each result from numerical simulations and mathematical models used in calculations should be verified by the real casting process. However, due to described above the limits of the industrial tests, the water modeling is used. Based on similarity conditions, the verification of the mathematical model used in the computer calculations can be performed by the water model [10]. The numerical simulation results supported by the water modeling outcomes can bring reliable conclusions, and simulated solutions can be adapted in the industrial conditions.

In this work, the numerical and physical simulations of the liquid steel flow in the one-strand tundish designed for the continuous slab casting process were performed. The influence of ladle shroud depth in the liquid steel was checked using the modified ladle shroud.

\section{Characteristic of the examined object}

The examined object was the one-strand wedge type tundish designed for the continuous steel casting. The nominal capacity of the considered object was equal 
to 30 tons. The tundish was equipped with the modified ladle shroud, the low dam with two overflow windows (installed before the place of lowering the tundish bottom), the stopper rod, and the submerged entry nozzle. The modification of the ladle shroud construction has consisted of expanding-compressing-expanding the liquid steel feeding stream at the tip of the considered object. That interference of the ladle shroud construction is to inhibit the velocity of the feeding stream of the liquid steel. Four immersion depth variants of the modified ladle shroud in liquid steel were tested $(0.1$, $0.2,0.3$, and $0.4 \mathrm{~m})$. The virtual model of the considered tundish with the ladle shroud immersion depth at $0.4 \mathrm{~m}$ in the liquid steel is presented in figure 1 . Also, technical drawings of the tundish and ladle shroud under consideration were shown.

In work [11], the research of the hydrodynamic structure of the liquid steel flow in the considered tundish with a conventional ladle shroud immersed at a depth of $0.1 \mathrm{~m}$ in liquid steel was carried out. The results show a $31.3 \%$ volume of the stagnant flow and $68.7 \%$ the active flow. Nevertheless, it should be known in mind that the results were obtained using slightly different thermal conditions and the entire length of the ladle shroud was not taken into account, which has a slight effect on the results of the calculations [12].

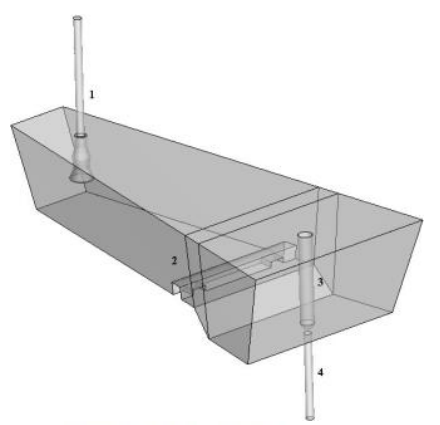

$B(0.15: 1)$

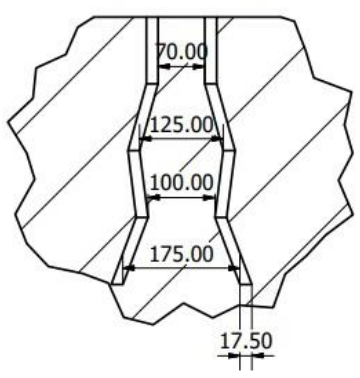

Fig. 1. The virtual model of the tundish with the modified ladle shroud immersed at a depth of $0.4 \mathrm{~m}$ in liquid steel: 1 - modified ladle shroud, 2 -dam, 3 - stopper rod, 4 - submerged entry nozzle, and technical drawings of the tundish and ladle shroud under consideration (dimensions in $\mathrm{mm}$ ).

\section{Research methodology}

The virtual tundishes with the modified ladle shroud in the Gambit computer program were generated. The 3D objects using the "bottom-up" and Boolean method 
and then were discredited were performed by a computational grid. Depending on the variant of the ladle shroud immersion depth in liquid steel, the computational grid in the range of 238,000-257,000 elements was equal. Then the boundary conditions of virtual tundishes were established. Finished virtual tundishes into the Ansys-Fluent computer program were exported, where the numerical simulations of the liquid steel flow were performed. The mathematical model used in the computer calculations solves the equation of a mass, momentum, and energy (energy equation in the non-isothermal simulations was solved). The results of numerical simulations in the isothermal conditions for the verification of the mathematical model used in the computer calculations were used. Besides, a system of equations was equipped with one of the following turbulence models: Standard k- $\varepsilon$, RNG k- $\varepsilon$, Realizable k- $\varepsilon$, BSL k- $\omega$, SST k- $\omega$ and LES (each numerical simulation for each research variant were repeated using one of the presented turbulence models). The considered mathematical model and the turbulence models were more fully described in the works $[1,13,14,15]$. The verification of the mathematical model allowed us to select the suitable turbulence model in the numerical simulation in the non-isothermal conditions. The simulated process was the continuous steel casting of the slab, which is characterized by dimensions $1.5 \times 0.225 \mathrm{~m}$. Casting velocity was equal to $0.015 \mathrm{~ms}^{-1}$. The inlet boundary condition at the beginning of ladle shroud was established and the parameters of the liquid steel flowed to the considered object were as follows: velocity $1.316 \mathrm{~ms}^{-1}$, turbulent kinetic energy $0.0173 \mathrm{~m}^{2} \mathrm{~s}^{-2}$, turbulent dissipation rate of kinetic energy $0.06514 \mathrm{~m}^{2} \mathrm{~s}^{-3}$ (using the turbulence model from group $\mathrm{k}-\varepsilon$ ), specific dissipation rate $4.4107141 \mathrm{~s}^{-1}$ (using the turbulence model from group $\mathrm{k}-\omega$ ) and temperature $1813 \mathrm{~K}$ (simulations in the non-isothermal conditions). The values of the turbulent kinetic energy, turbulent dissipation rate of kinetic energy, specific dissipation rate were calculated using equations described in the literature $[16,17]$. The boundary condition of the tundish upper surface was established by the free surface (which was an imitation of the liquid steel/slag boundary). Furthermore, the heat fluxes on walls and an upper surface of the tundish in the non-isothermal simulations were taken into account $\left(-2600 \mathrm{Wm}^{-2}\right.$ for the tundish walls and bottom, $-15000 \mathrm{Wm}^{-2}$ for the free surface, and $1750 \mathrm{Wm}^{-2}$ for the devices immersed in the liquid steel). The physicochemical properties of the liquid steel in the isothermal simulations are as follows: density $7010 \mathrm{kgm}^{-3}$, viscosity $0.007 \mathrm{kgm}^{-1} \mathrm{~s}^{-1}$, whereas in the non-isothermal calculations was additional established thermal conductivity $41 \mathrm{Wm}^{-1} \mathrm{~K}^{-1}$, heat capacity $750 \mathrm{Jkg}^{-1} \mathrm{~K}^{-1}$. Also, the density of the liquid steel in the non-isothermal simulations was solved by the polynomial function of the temperature [18]. The mathematical model used in the calculations was solved by the control volume method using the second-order upwind discretization of the sequential solver. The coupling of the pressure and velocity fields were solved by the semi-implicit method for pressure-linked equations-consistent (SIMPLEC) algorithm. Furthermore, the residue levels were kept on a level at least $10^{-3}$, which was also adopted in the works [11, 13, 19]. Numerical simulations using turbulence models from the RANS group were performed in a steady-state. Also, the $\mathrm{y}^{+}$ parameter (30-60), which indicates the proper grid compaction at the boundary layers was respected. The numerical simulation using the LES turbulence model required a finer mesh and a transient simulation. Therefore, in the resulting computer simulation file using the Standard k- $\varepsilon$ turbulence model, the LES model had assigned and then transient numerical simulation has been performed for four average residence times 
of which the results were statistically averaged over the last two average residence times. Besides, the Wall-Adapting Local Eddy-Viscosity WALE subgrid model in the calculations using the LES turbulence model was adopted.

The results of numerical simulations were residence time distribution (RTD) E type curves, flow and temperature fields of liquid steel. The E curves were generated by pulse introducing the marker into the ladle shroud and recording the concentration of the marker in the submerged entry nozzle. Furthermore, the concentration and the time in the E curves were calculated into the dimensionless values. The dimensionless concentration was solved from the ratio of marker and steel mass (in the tundish) divided through the marker concentration in the time. Whereas, the dimensionless time was calculated from the relation of steel mass (in the tundish) and the mass flow rate of liquid steel in the ladle shroud divided by a measurement time. The equations of the dimensionless concentration and the time were described in detail in the literature [19, 20]. The user-defined scalar (UDS) transport equation was used to solve the marker flow in the working space of tundish. E curves allowed to calculate the active (which consists of plug and ideal mixing flow volume) and stagnant liquid steel flow volumes using the equations described in the work [20]. The registration of the RTD curve in the transient simulation was performed. Whereas, the RTD curve in the simulation using the LES turbulence model was done after reaching two average residence times (since the LES turbulence model was switched on).

The laboratory experiments were performed in the next stage of research, which based on the water modeling technique [10]. The research object was the glass model of tundish with the performed of the stereolithography method ladle shroud, which was made on a $2: 5$ scale [11]. The nominal capacity of the tundish model was equal to $210 \mathrm{~L}$. The object was equipped with the marker injector at the beginning of the ladle shroud model. Furthermore, the laboratory stand consisted of a hydraulic system with the flow meter to provide and control proper liquid flow in the tundish model. The laboratory stand-in figure 2 is shown. According to the similar kinematic viscosity at $20^{\circ} \mathrm{C}$ with liquid steel at $1600{ }^{\circ} \mathrm{C}$, the modeling liquid was water. Also, the Froude criterion during laboratory tests was fulfilled, which provide the similarity of inertia and gravitational forces between a real tundish and a water model of tundish [10]. The reduced intensity of the liquid flow during the water modeling using equation 1 was calculated.

$$
Q_{\text {water_model }}=\lambda^{2.5} \times Q_{\text {actual_tundish }}
$$

where: $Q_{\text {water_model }}$ is the intensity of the water flow during the laboratory experiments $\left(Q_{\text {water_model }} \approx 30 \mathrm{Lmin}^{-1}\right)\left[\mathrm{Lmin}^{-1}\right], \lambda$ is the scale factor [-], $Q_{\text {actual_tundish }}$ is the intensity of liquid steel flow $\left(Q_{\text {actual_tundish }}=303.75 \mathrm{Lmin}^{-1}\right)\left[\mathrm{Lmin}^{-1}\right]$.

The results of the water modeling were the E curves, which the generation consisted on the pulse introducing marker in the form of the sodium chloride $\mathrm{NaCl}$ water solution into the ladle shroud model (while through the tundish model flow "clean" water) and recoding the salinity of the water in the submerged entry nozzle by a conductometric sensor. The marker was contained a $2 \%$ salt (according to similar density with "clean" water) and its amount was equal to $250 \mathrm{ml}$. The measurement 
of the water salinity was performed every $10 \mathrm{~s}$ through two dimensionless times (1276.8 s). The whole measurement operation six times was repeated.

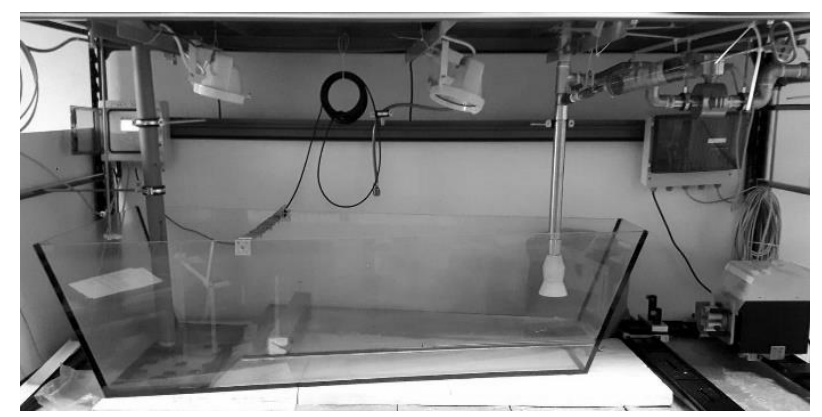

Fig. 2. The physical model of the tundish.

The variant with the modified ladle shroud immersion depth at a $0.4 \mathrm{~m}$ in the liquid steel for the performance of the mathematical model verification was selected, due to using that immersion in the industrial conditions in one of the domestic steel plants (using a conventional ladle shroud). The verification has consisted of the comparison $\mathrm{E}$ curves from the numerical simulation in the isothermal conditions with measurement points from the laboratory experiment. The quality and quantity analysis were performed. The quality analysis consisted of the visual assessments between the $\mathrm{E}$ curve shapes and positions of measurement points. In contrast, the quantity analysis consisted of the comparison of the average time elapsed required to achieve maximum concentration of the marker during water modeling (which is known as $\Theta_{\max }$ parameter)with the numerical simulation results. In the range of the quantitative analysis, the comparison of the average active and stagnant flow volumes between water modeling results and numerical simulation results was also performed. Furthermore, the quantitative analysis of the measurement point positions in comparison with the E curve position of the individual numerical simulation result was performed using equation 2 . The solution of this equation was the average percentage difference between the average measurement point location and $\mathrm{E}$ curve from the numerical simulation.

$$
\bar{D}_{E_{\text {curve }}}=\frac{\sum_{\Theta=0}^{2} \Delta C t}{N_{M}} \times 100 \%
$$

where: $\bar{D}_{E_{\text {curve }}}$ is the average percentage difference between average measurement point location and $\mathrm{E}$ curve from numerical simulation [\%], $\Delta C t$ is the dimensionless marker concentration difference in $t$ time between the average $\mathrm{NaCl}$ concentration from water modeling and the marker concentration from numerical simulation [-], $N_{M}$ is the number of measurements for each experiment [-], $\Theta$ is the dimensionless time [-]. 


\section{Research results}

Verification of the mathematical model used in the numerical calculations

The measurement points from the water modeling were compared with the $\mathrm{E}$ curve from the numerical simulations in the isothermal conditions for tundish case 4 (figure 3).

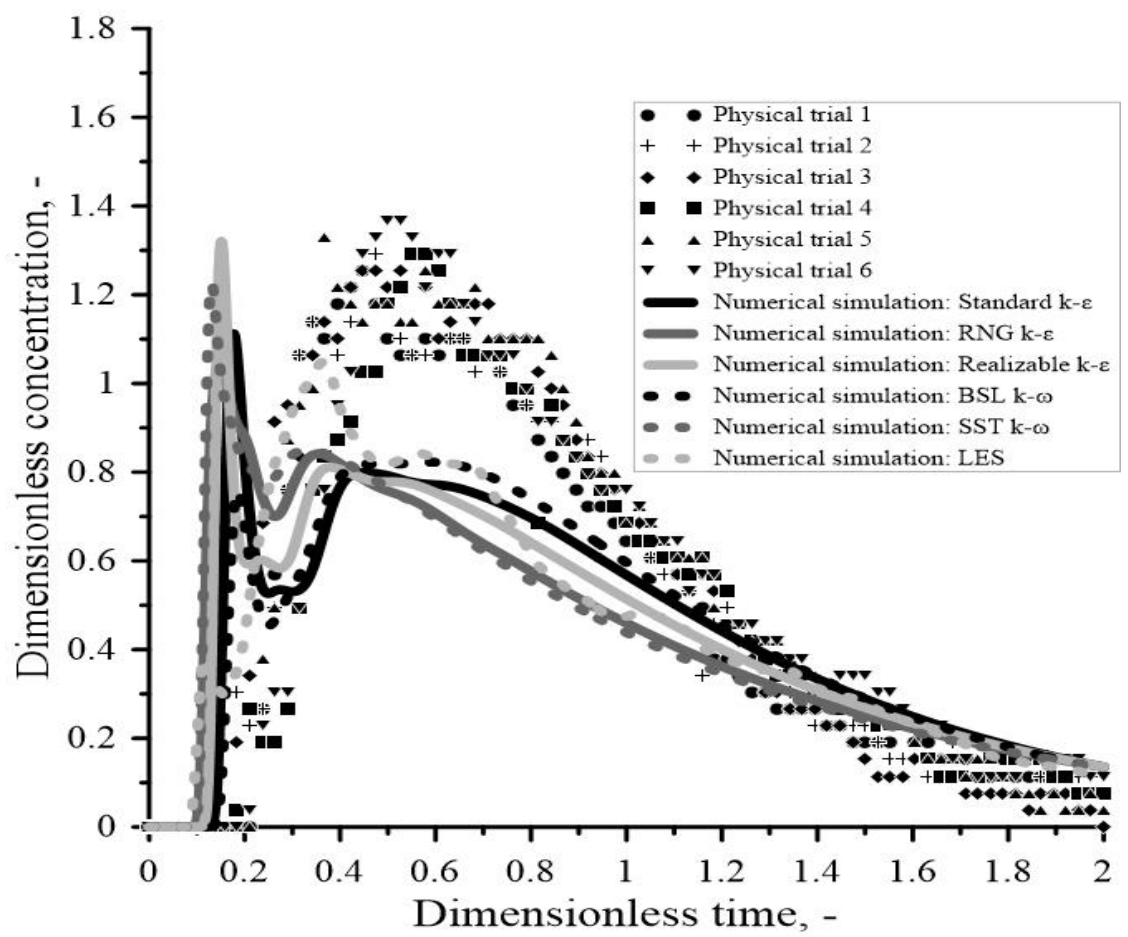

Fig. 3. E curves for numerical simulations in isothermal conditions with physical trials.

The shapes of the E curve from each numerical simulation (using the one selected turbulence model) differed from each other. In the computer calculations with the LES and the BSL k- $\omega$ turbulence model, it can be seen the existence of channel flow type, due to the appearance of the two peaks in the E curve shape. Whereas, in the other numerical simulation results, it can be seen one explicit peak at about 0.15 of the dimensionless time. Then, the $\mathrm{E}$ curves from the numerical simulations with the use of Standard $\mathrm{k}-\varepsilon, \mathrm{RNG} \mathrm{k}-\varepsilon$, SST $\mathrm{k}-\omega$, and LES turbulence model, together with decreasing dimensionless concentration is visible the existence recirculation flow. The analysis of the measurement point positions from water modeling the appearance of one peak at about 0.52 of the dimensionless time was shown. The quality analysis between the water modeling measurements and numerical simulations results in the lowest differences using the BSL $\mathrm{k}-\omega$ turbulence model in the numerical calculations were indicated. Nevertheless, the shape of the curve E was not perfectly matched the location of the measurement points. Because the RTD curves describe the macro hydrodynamic conditions and the occurred differences are associated with the local different structures of the liquid flow in the mathematical and physical model. The comparison of the RTD 
curves or the selected parameters does not run out of the issues related to the improvement of the hydrodynamic structure imitation. However, it answers which the turbulence model can be used, in order to gain similar conditions, like in the actual tundish. The comparison of the RTD curves between the results of numerical and physical simulations is a frequently used method to the assessment of obtained results from the numerical calculations, primarily that the turbulence model determines the results of the calculations $[15,19,21,22,23,24]$.

Table 1. The hydrodynamic condition for different turbulence models for the tundish.

\begin{tabular}{|c|c|c|c|c|c|c|c|}
\hline \multirow{2}{*}{ Parameter } & \multirow{2}{*}{$\begin{array}{l}\text { Average } \\
\text { from } \\
\text { water } \\
\text { modeling }\end{array}$} & \multicolumn{6}{|c|}{$\begin{array}{l}\text { Numerical simulation results in isothermal } \\
\text { conditions }\end{array}$} \\
\hline & & $\begin{array}{l}\text { Standard } \\
\mathrm{k}-\varepsilon\end{array}$ & $\begin{array}{l}\mathrm{RNG} \\
\mathrm{k}-\varepsilon\end{array}$ & $\begin{array}{c}\text { Realizable } \\
\text { k- } \varepsilon\end{array}$ & $\begin{array}{l}\text { BSL } \\
k-\omega\end{array}$ & $\begin{array}{l}\text { SST } \\
\mathrm{k}-\omega\end{array}$ & LES \\
\hline$P F[\%]$ & 34.87 & 13.50 & 10.70 & 11.15 & 33.41 & 9.29 & 20.00 \\
\hline$M F[\%]$ & 50.13 & 63.55 & 58.40 & 62.04 & 45.40 & 58.17 & 53.02 \\
\hline$S F[\%]$ & 15.00 & 22.95 & 30.90 & 26.81 & 21.19 & 32.54 & 26.98 \\
\hline$(\Delta P F+\Delta S F)[\%]$ & & 29.32 & 40.07 & 35.53 & 7.65 & 43.12 & 26.85 \\
\hline$\Theta_{\max }[-]$ & 0.52 & 0.18 & 0.15 & 0.15 & 0.59 & 0.13 & 0.37 \\
\hline$\Delta \Theta_{\max } \times 100 \%$ & & 34.11 & 36.98 & 36.65 & 7.25 & 38.67 & 15.05 \\
\hline $\bar{D}_{E_{\text {curve }}}[\%]$ & & 17.42 & 21.58 & 18.65 & 14.69 & 22.67 & 16.38 \\
\hline
\end{tabular}

The quality analysis is unsatisfactory; therefore, the quantitative analysis was performed and the results in table 1 were shown. The average percentage volume of the plug $(P F)$, ideal mixing $(M F)$ and stagnant flow ( $S F$ )for water modeling results were counted and it was compared with flow volumes from each numerical simulations. The $\triangle P F$ and $\triangle S F$ parameter were summed $(\triangle P F$ and $\triangle S F$ are the plug and stagnant flow differences between the flow volumes of the water modeling and flow volumes of the numerical simulation) and it can be seen that the lowest differences in the shape of the flow volumes were given using the BSL $\mathrm{k}-\omega$ turbulence model in the numerical calculations $(7.65 \%)$. Then, the analysis of $\Theta_{\max }$ parameter was performed, which describes the moment of achievement of the highest marker concentration in the submerged entry nozzle. Whereas, the $\Delta \Theta_{\max }$ parameter describes the differences in $\Theta_{\max }$ between the water modeling results and the numerical simulation results. That analysis of the slightest discrepancies using the BSL k- $\omega$ of the turbulence models tested was also shown $(7.25 \%)$. In the end, the average percentage difference between the average measurement point location and the $\mathrm{E}$ curve from the numerical simulation was 
calculated ( $\bar{D}_{E_{\text {curve }}}$ parameter). The use of the BSL k- $\omega$ turbulence model was caused by the obtainment of the smallest quantity of $\bar{D}_{E_{\text {curve }}}$ parameter $(14.69 \%)$.

The performed qualitative and quantitative analysis of the BSL k- $\omega$ was the most beneficial turbulence model used in the numerical calculations. Therefore, the BSL k- $\omega$ turbulence model for the performance of the numerical simulations in the nonisothermal conditions was selected.

\section{Numerical simulationresults in the non-isothermal conditions}

The numerical simulations in the non-isothermal conditions were performed using the verified mathematical model (using the BSL k- $\omega$ turbulence model). The analysis of the liquid steel flow hydrodynamic structure with the emphasis on liquid steel flow and temperature fields were done. Furthermore, the influence of the ladle shroud immersion depth in the liquid steel on the active and the stagnant flow volume was checked.

The figure 4 shows the liquid steel flow fields on a plane being symmetry of the considered tundish. Due to a more straightforward description of the hydrodynamic structure, the ladle shroud immersion depth at $0.1 \mathrm{~m}, 0.2 \mathrm{~m}, 0.3 \mathrm{~m}, 0.4 \mathrm{~m}$ in liquid steel were adduced as follows case 1 , case 2 , case 3 , case 4 . In case 1 (figure 4a), two horizontal circulation streams can be seen from filling the place of the tundish to the dam position. Whereas, a vertical circulation stream above the dam was visible. In cases: 2,3 , and 4 (figure $4 \mathrm{~b}, \mathrm{c}, \mathrm{d}$ ), a two circulation streams near the tundish bottom in the filling space were generated by the feeding stream of liquid steel. Furthermore, in the case 2 and 4 the backflows were visible, which flow from the stopper rod zone to the circulation stream behind the dam. In case 3, a horizontal circulation stream near the free surface and the ladle shroud was noted, and the wider influence of a horizontal circulation stream from the right tundish wall to the tundish center. Also, in case 4, a horizontal circulation stream above the dam and near stopper rod was seen. The flow fields on the plane, which pass through the ladle shroud axis in the viewpoint of the stopper rod for better understand the liquid steel flow hydrodynamic structure in the considered cases were generated (figure 5). The asymmetric liquid steel flow in all considered cases was noted due to the flow direction of the feeding stream liquid steel. In the cases 1-3 (figures 5a, b, c), the mainstream of the liquid steel was flowing towards the right wall-bottom corner, whereas, in the case 4 (figure $5 \mathrm{~d}$ ), it was flowed towards to the left wall-bottom corner. The feeding stream of liquid steel generated the widespread influence of a circulation stream along the bottom and left wall in case 1 . Whereas, in cases 2 and 3, the character of flow fields were similar, according to the creation of three circulation streams along the right wall, left wall/bottom and left wall/free surface of the considered tundish. Furthermore, the broad influence of two circulation streams in case 4 along the left and right tundish wall were identified. Summarizing the analysis of figures 4 and 5 , it was noted that the immersion of the ladle shroud to a depth of $0.3 \mathrm{~m}$ in the liquid steel causes a whole generation of the circulation streams on both analyzed planes. Practically, the entire of the analyzed planes were covered by circulation streams. This may indicate the intensification of the mixing phenomenon of liquid steel in the tundish working space. 


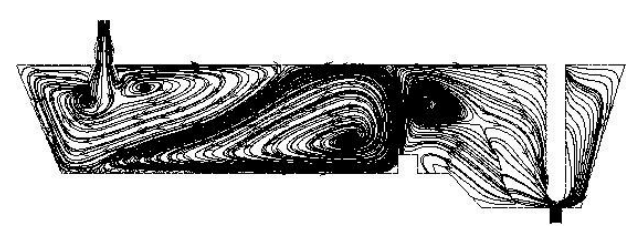

a)

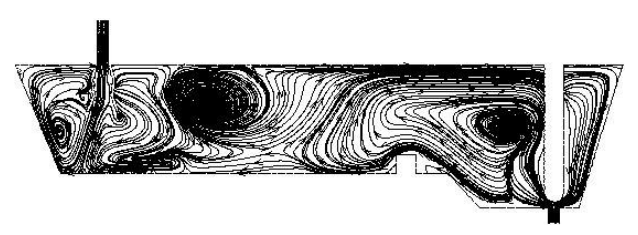

c)

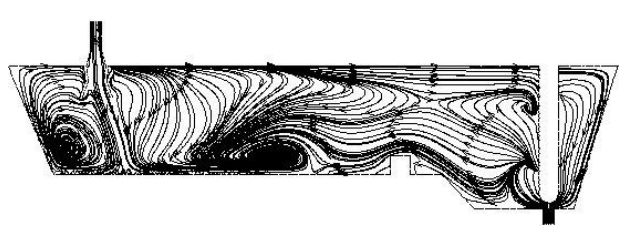

b)

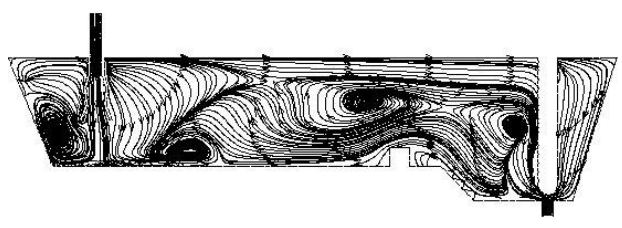

d)

Fig. 4. Fields of the liquid steel flow in the considered tundish for ladle shroud immersion depth at a) $0.1 \mathrm{~m}, \mathrm{~b}$ ) $0.2 \mathrm{~m}, \mathrm{c}$ ) $0.3 \mathrm{~m}, \mathrm{~d}$ ) $0.4 \mathrm{~m}$ in liquid steel.

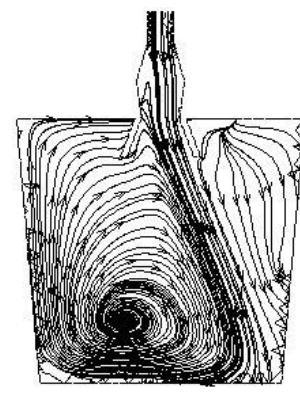

a)

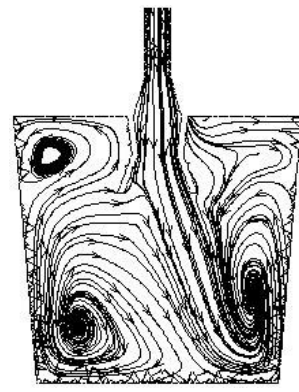

b)

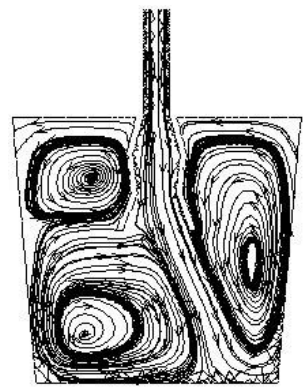

c)

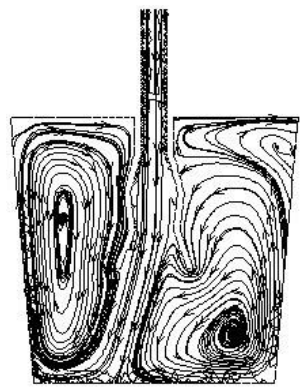

d)

Fig. 5. Fields of the liquid steel flow in the tundish inlet zone for ladle shroud immersion depth at a) $0.1 \mathrm{~m}, \mathrm{~b}$ ) $0.2 \mathrm{~m}, \mathrm{c}$ ) $0.3 \mathrm{~m}, \mathrm{~d}$ ) $0.4 \mathrm{~m}$ in liquid steel.

Figure 6 shows the liquid steel temperature fields on the tundish symmetry plane. The heat homogenization in all research cases was similar, due to the same temperature of the liquid steel near the submerged entry nozzle (1809 K). Whereas, according to the research case, the temperature distribution in the tundish working space was different. Generally, the higher temperature fields in cases 1 and 2 (figure 6a, b) along the tundish bottom were distributed. While, the lower temperatures it can be seen near the tundish bottom from the circulation stream place (figure $4 \mathrm{c}, \mathrm{d}$ ) to the lowering of the tundish bottom. Besides, the small local circulating streams were not favorable to the homogenization of the liquid steel temperature in the tundish working space. 


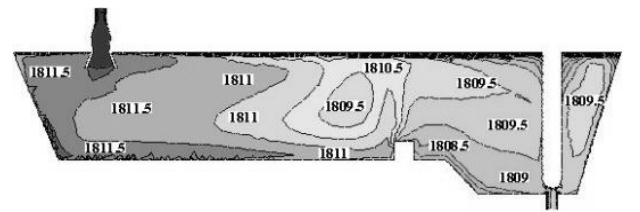

a)

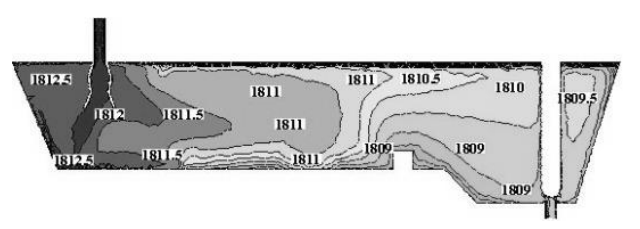

c)

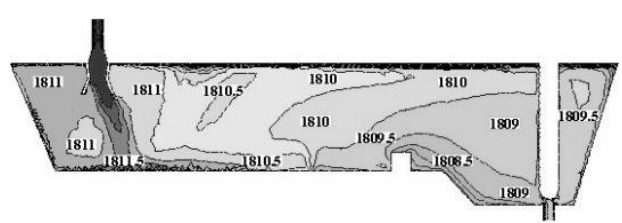

b)

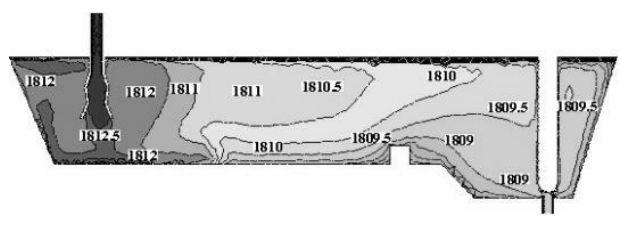

d)

Fig. 6. Fields of the liquid steel temperature in the considered tundish for ladle shroud immersion depth at a) $0.1 \mathrm{~m}, \mathrm{~b}) 0.2 \mathrm{~m}, \mathrm{c}) 0.3 \mathrm{~m}, \mathrm{~d}) 0.4 \mathrm{~m}$ in liquid steel.

The E curves to assess the influence of ladle shroud immersion depth in the liquid steel on the intensification of active flow volume in the considered tundish were generated (figure 7). The ladle shroud immersion depth at $0.1 \mathrm{~m}$ and 0.3 in the liquid steel caused the generation of the E curve peak at a similar dimensionless time (0.27). Then, the E curve shape of cases 1 and 3 were different due to the recirculation flow. The explicit $\mathrm{E}$ curve peak in case 2 at 0.14 of the dimensionless time was noted. The $\mathrm{E}$ curve shape in case 2 the small volume of the plug flow was indicated, due to the rapid drop of the marker dimensionless concentration. However, the wide plug flow volume in case 4 can be seen because of the maintain high amount of the marker dimensionless concentration (up to 0.38 of the dimensionless time). Furthermore, the channel type flow in case 4 was noted due to the appearance of the two peaks of the E curve.

The relation between active ( $P F$ and $M F$ ) and the stagnant flow volume in figure 8 was shown. The research variant with the ladle shroud immersion depth at $0.3 \mathrm{~m}$ in the liquid steel was characterized by the lowest volume of the stagnant flow $(19.62 \%)$. Whereas, according to the volume flow shapes, the worst immersion depth in the liquid steel of the ladle shroud at $0.2 \mathrm{~m}$ levels was noted, (the active and stagnant flow volume was equal to $67.51 \%$ and $32.49 \%$, respectively). The highest amount of the plug flow volume in case 4 was observed $(23.31 \%)$, which can indicate the generation well conditions for decreasing the transition zone during the sequential casting process. 


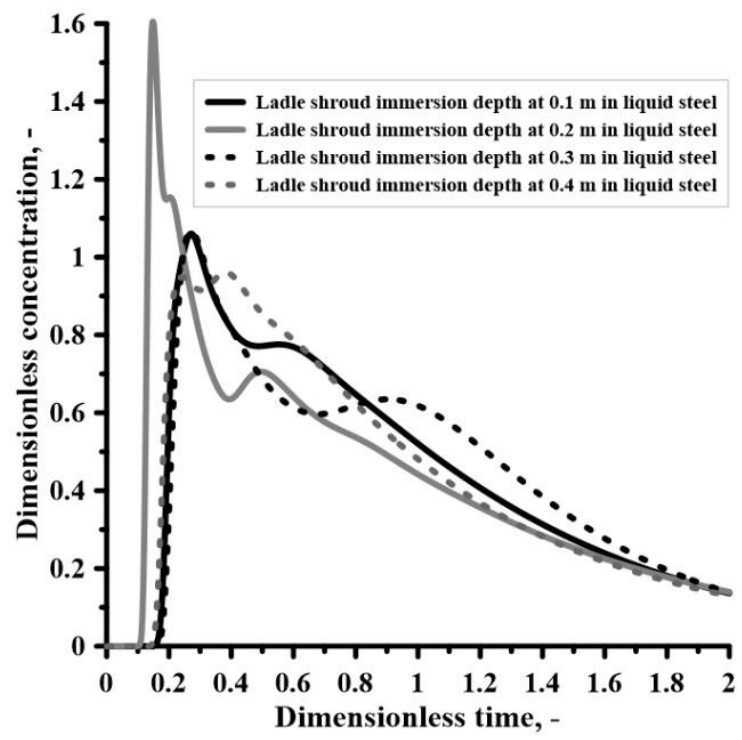

Fig. 7. E curves for the considered research cases.

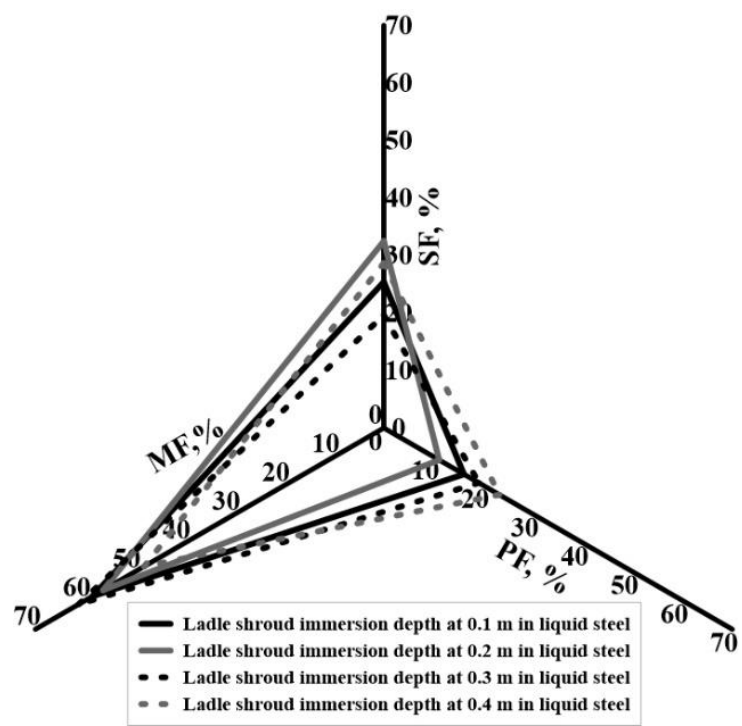

Fig. 8. Percentage volumes of the liquid steel flow for the considered research cases: SF - Stagnant flow volume, PF - Plug flow volume, MF - Ideal mixing flow volume. 


\section{Summary}

The tests carried out to provide complete information on the use of the modified ladle shroud immersion depth in the liquid steel. The research results allow the following conclusions:

- The mathematical model verification based on the quality and quantity analysis of the BSL k- $\omega$ turbulence model was characterized by the best correlation with the water modeling results.

- The deeper immersion of the modified ladle shroud was not a significant influence on the thermal homogenization in the tundish working space and the temperature of the flowed liquid steel to the mold.

- The ladle shroud immersion depth at $0.3 \mathrm{~m}$ in the liquid steel the highest amount of the active flow volume $(80.38 \%)$ was generated among the tested research variants.

\section{Acknowledgments}

The research work carried out in the range of the statutory research of the Department of Metallurgy and Metals Technology, Czestochowa University of Technology, no. of work BS/MN-204-301/2018.

\section{References}

[1] J. Zhang, J. Li, Y. Yan, Z. Chen, S. Yang, J. Zhao, Z. Jiang: Metall Mater Trans B, 47 (2016) 495-507.

[2] J. Zhang, S. Yang, M. Li, Z. Chen, Z. Jiang, J. Li:Ironmak Steelmak, 44 (2017) $732-737$.

[3] S. Garcia-Hernandez, R.D. Morales, J.D.J. Barreto, I. Calderon-Ramos, E. Gutierrez: Steel Res Int, 87 (2016)1154-1167.

[4] G. Solorio-Diaz, R.D. Morales, A. Ramos-Banderas: Int J Heat Mass Tran, 48 (2005) 3574-3590.

[5] D. Chatterjee: Adv Mat Res, 585 (2012) 359-363.

[6] D. Chatterjee: Am J Min Metall, 4 (2017) 1-31.

[7] D. Chatterjee: J Achiev Mater Manuf Eng, 81 (2017) 18-34.

[8] L. Zhong, B. Li, Y. Zhu, R. Wang, R. Wang, X. Zhang: ISIJ Int, 47 (2007) 8894.

[9] A. Tripathi, S.K. Ajmani: ISIJ Int, 51 (2011) 1647-1656.

[10] D. Mazumdar: Trans Indian Inst Met, 66 (2013) 597-610.

[11] A. Cwudziński: Steel Res Int, 85 (2013) 902-917.

[12] M. Bartosiewicz, A. Cwudziński: Hutnik-Wiad Hut, 84 (2017) 483-488 (in Polish)

[13] A. Kumar, D. Mazumdar, S.C. Koria:ISIJ Int, 48 (2008) 38-47.

[14] F.R. Menter: AIAA Journal, 32 (1994) 1598-1605.

[15] M.I.H. Siddiqui, P.K. Jha: ISIJ Int, 54 (2014) 2578-2587.

[16] A. Asad, C. Kratzsch, R. Schwarze: Steel Res Int, 87 (2016) 181-190.

[17] G. Solorio-Diaz, R.D. Morales, J. Palafax-Ramos, L. Garcia-Demedices, A. Ramos-Banderas: ISIJ Int, 44 (2004) 1024-1032.

[18] A. Cwudziński: Met Res Tech, 111 (2014) 45-55.

[19] G. Wang, M. Yun, C. Zhang, G. Xiao: ISIJ Int, 55 (2015) 984-992.

[20] Y. Sahai, T. Emi: Tundish technology for clean steel production, first ed., World Scientific Publishing Co. Pte. Ltd., Singapore, 2007. 
[21] J. Jowsa, A. Cwudziński: Arch Metall Mater, 55 (2010) 477-488.

[22] A. Kumar, S.C. Koria, D. Mazumdar: ISIJ Int, 44 (2004) 1334-1341.

[23] T. Merder, J. Pieprzyca: Steel Res Int, 83 (2012) 1029-1038.

[24] M. Warzecha, T. Merder, H. Pfeifer, J. Pieprzyca:Steel Res Int, 81 (2010) 987993.

\section{(c) (i) CreativeCommonsLicense}

This work is licensed under a Creative Commons Attribution 4.0 International License. 